\title{
Combined Treatment of Real Sugar Industry and Sago Wastewater Using Hybrid Upflow Anaerobic Sludge Blanket (HUASB) Reactor
}

\author{
T. Kavimani*†, K. Balaji** and G. Gnanapragasam*** \\ $* \dagger$ Department of Civil Engineering, Government College of Engineering, Thanjavur, Tamilnadu, India \\ **Department of Civil Engineering, University College of Engineering, Anna University, Panruti, Tamilnadu, India \\ ***Department of Chemical Engineering, VSB Engineering College, Karur, Tamilnadu, India \\ †Corresponding author: T. Kavimani; tkavimani@gmail.com
}

Nat. Env. \& Poll. Tech.

Website: www.neptjournal.com

Received: $15-12-2019$

Revised: 29-12-2019

Accepted: 03-01-2020

Key Words:

Biogas

HUASB reactor

Sago wastewater

Sugar industry

\begin{abstract}
This paper presents the performance of Hybrid Upflow Anaerobic Sludge Blanket (HUASB) reactor in treating combined real sugar industry and synthetic sago effluents. Sugar industry is one of the most important agricultural industries which discharge the effluent in a huge quantity that creates environmental problems. The disposal of untreated sugar industry effluent in soils and water bodies has received much attention since decades ago. So, in this study, it was decided to inoculate the HUASB reactor with seed sludge from the existing anaerobic digester treating sago wastewater and then it was started by using synthetic sago wastewater, and then it was fed with the combined real sugar industry and synthetic sago wastewater. The reactor was fed with the combined effluents of a real sugar industry and synthetic sago wastewater at different mixing ratios having the Chemical Oxygen Demand (COD) ranging from 4450 to $5360 \mathrm{mg} / \mathrm{L}$ with HRT of 24 hours. The $\mathrm{pH}$, COD removal, volatile fatty acid (VFA), alkalinity and biogas production were monitored for various inlet of COD values. The inlet and outlet $\mathrm{pH}$ was between the range of 5.62 to 7.36 and 7.53 to 8.18 respectively. The VFA and alkalinity varied from 36 to $84 \mathrm{mg} / \mathrm{L}$ and 926 to $998 \mathrm{mg} / \mathrm{L}$ respectively. The biogas production varied from 10.6 to 13.2 $\mathrm{L} / \mathrm{d}$. The maximum COD removal of $94.4 \%$ and the biogas production of $13.2 \mathrm{~L} / \mathrm{d}$ was reported at $\mathrm{pH}$ 8.11 at the mixing ratio of 60/40 (sago/sugar industry wastewater).
\end{abstract}

\section{INTRODUCTION}

Sago is a main agro-based product found in various parts of the world. Products from tapioca like starch and sago introduced in India since1940s onwards. Processing of tapioca need 20,000-30,000 L of water per ton of sago; besides it produces same quantity of wastewater which is extremely organic, foul smelling and acidic. Most of the starch units generate effluent within the range of $200-300 \mathrm{~m}^{3} / \mathrm{d}$. Several studies reported that the sago industry wastewater may bring about drastic ecological imbalances in the nearby agro ecosystems if it is not treated properly (Murthy \& Patel 1961, Saroja \& Sastry 1972, Gnanapragasam et al. 2010, Senthilkumar et al. 2011).

Sugar industry contributes to the development of the economy in many countries, but arguably harms the environment (Ndobeni et al. 2019). The conversion of natural habitats for cane cultivation in coastal areas and tropical islands has led to critical environmental damage, loss of biodiversity and ecosystem services at landscape levels (Rein et al. 2011). These wastes not only represent a threat to the environmental quality but also possess a potential energy value which is not fully utilized despite the fact that they are cheap and abundant in most parts of the world (Hampannavar \& Shivayogimath 2010).

Anaerobic treatment converts the wastewater organic pollutants into small amount of sludge and large amount of biogas as source of energy (Ayati \& Ganjidoust 2006). Whereas aerobic treatment needs external input of energy for aeration. The upflow anaerobic sludge blanket (UASB) reactor is by far the most widely used high rate anaerobic treatment system for variety of wastewater (van Haandel \& Lettinga 1994). The anaerobic biological sludge blanket systems proposed over recent years have elicited considerable interest because of their good removal efficiencies of organic substrates, their relatively simple layout and the low capital and operating costs. Granular biomass with high methanogenic activity and excellent settling properties can be cultivated in these reactors (Buzzini et al. 2006).

The investigation is on the feasibility of treatment of real sugar industry effluent under bench scale hybrid upflow anaerobic sludge blanket reactor of stressed loadings. Shortening the start-up time bears practical significance as 
it can raise attractiveness of HUASB reactor applications by saving time and cost. After the start-up process the reactor were operated at various mixing ratio of real sugar industry and synthetic sago wastewater and COD, $\mathrm{pH}, \mathrm{VFA}$, alkalinity and biogas were monitored regularly.

\section{MATERIALS AND METHODS}

\section{Biomass}

In the present research, materials were collected from sago factory which is located in Salem. The unspecified microoraganims present in the granular sludge from the starch effulent were used in the study. The sludge was completely washed before loading and filtered in a mesh in order to minimize the inorganic components present in the granules. About $60000 \mathrm{mg} / \mathrm{L}$ content of sludge was estimated as volatile suspended solids (APHA 2005).

\section{Wastewater}

Sugar industry: Real sugar industry wastewater was collected from M.R.Krishnamurthy Co-operative sugar mill Ltd, Sethiyathope village, Chidambaram Taluk, Cuddalore District, Tamil Nadu, India. The characteristics were immediately analysed before feeding the reactor.
Synthetic sago: In this research synthetic sago wasterwater was prepared in which nitrogen and phosphorus were added along with starch and minerals in the ratio of 5:1:550. Ferric chloride, zinc sulphate, copper sulphate present as nutrients were added to the reactor at the concentration of $1.0 \mathrm{ml} / \mathrm{L}$ (Bhatti 1995, Arshad et al. 2009).

\section{Experimental Setup}

In this research study benchscale HUASB reactor was designed and fabricated using perspex tube (Fig 1). The reactor of about $20 \mathrm{~L}$ volume has a total height of $1.42 \mathrm{~m}$ with $1.17 \mathrm{~m}$ as the effective height and $0.15 \mathrm{~m}$ diameter. The upper most part of the reactor has solid-gas-liquid separater (GLSS) portion which is mainly for biogas collection in the form of inverted conical funnel. The gas produced from the reactor can be estimated by water displacement method. A peristaltic pump (20 ppm) was used to pump the substrate into the reactor with constant discharge flow. Bioballs as support media were used in this study and placed in top segment in the reactor. Totally 152 bioballs were kept in the reactor to prevent the escape of biogranules from the reactor. Five sampling ports at different heights were installed for ease of collection of samples for analysis. The reactor was operated at $30 \pm 3^{\circ} \mathrm{C}$.

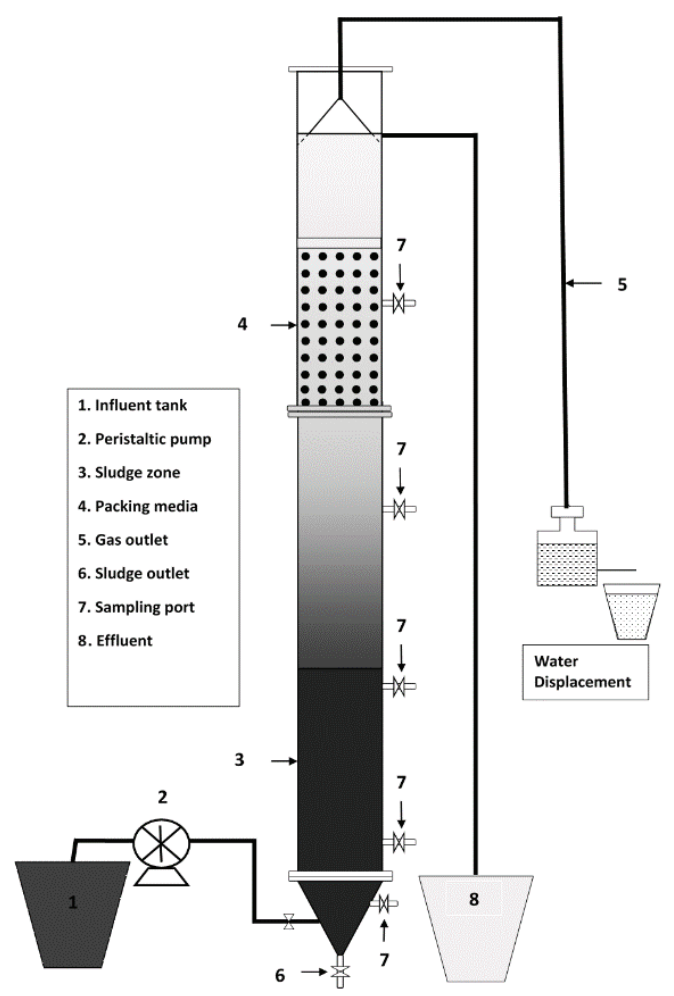

Fig. 1: Schematic representation of Bench Scale Hybrid Anaerobic Slude Blanket Reactor. 


\section{RESULTS AND DISCUSSION}

\section{COD Conversion and Removal Performance}

After mixing the wastewater of sago and sugar industries, the COD values of influent and reactor outlet are presented in Fig. 2. The COD values range from 5360 to $4450 \mathrm{mg} / \mathrm{L}$. The COD removal efficiency for different effluent mixing proportions at $24 \mathrm{~h}$ HRT is presented in Fig. 3.

The COD removal efficiency was in the range of 61.9$94.4 \%$. At effluent mixing ratio of $60 / 40$ (sago $60 \%$, sugar $40 \%$ ), the overall COD removal efficiency was $94.4 \%$.

\section{pH, VFA and Alkalinity}

The $\mathrm{pH}$ values of the inlet and outlet of HUASB reactor are presented in Fig. 4. The HUASB reactor effluent $\mathrm{pH}$ increased to a value beyond 7 and always remained so (range
7.53-8.18). The VFA values in HUASB reactor were in the range of 36-84 mg/L (Fig. 5) and VFA value increased when the sugar industry effluent proportion was increased. The HUASB reactor effluent alkalinity was in the range of 926-998 mg/L (Fig. 6).

\section{VFA/Alkalinity Ratio}

The Fig. 7 shows VFA/Alkalinity ratio (VFA/AL) in the HUASB reactor. The effluent of HUASB reactor had VFA/ AL ratio less than 0.089 . It means that process in HUASB reactor is under stable condition.

Senthilkumar et al. (2009) reported that the VFA/Alk ratio for acidogenic and H UASB reactors is in the range of 1.3-1.5 and 0.04-0.09. A stable anaerobic treatment system requires a balance among all microorganisms. The maintenance of this balance is normally indicated by a low VFA concentra-

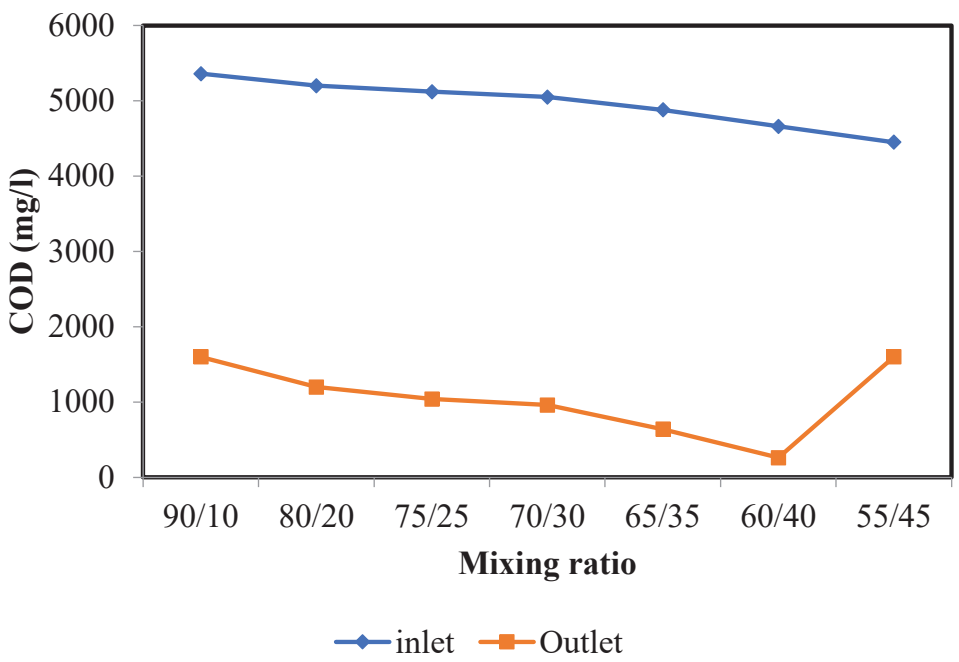

Fig. 2: COD values at various mixing ratios.

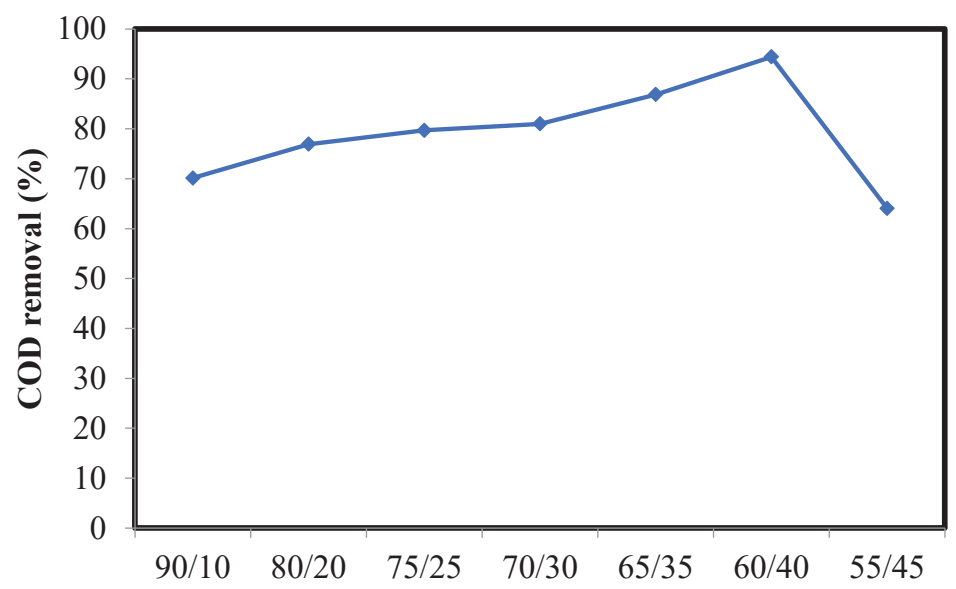

Fig. 3: COD removal efficiency at various mixing ratios. 


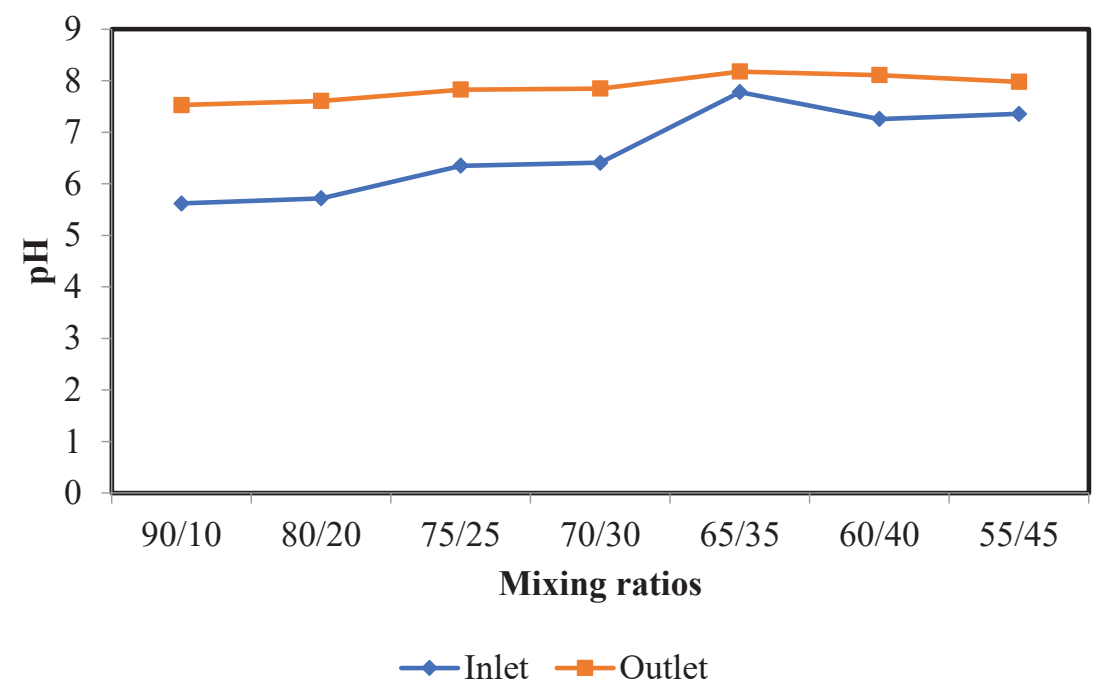

Fig. 4: $\mathrm{pH}$ values at various mixing ratios.

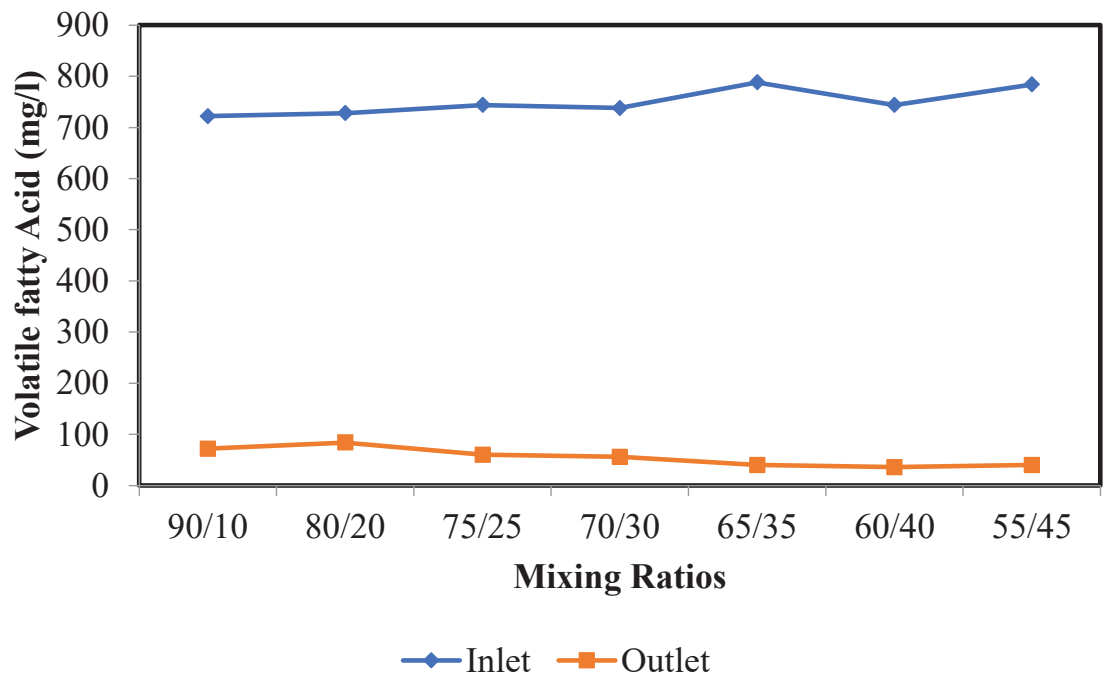

Fig. 5: VFA concentration at various mixing ratios.

tion, appropriate $\mathrm{pH}$ and VFA/Alk ratio. If a UASB reactor is stable, the VFA/Alk ratio of the reactor effluent must be lower than 0.4 (Behling et al. 1997). Sanchez et al. (2005) stated that the optimum ratio of VFA to alkalinity should be less than 0.3 or 0.4 for UASB reactor.

\section{Biogas Production}

Fig. 8 shows the biogas production at various mixing ratios such as 90/10, 80/20, 75/25, 70/30, 65/35, 60/40 and 55/45 for HUASB reactor. The maximum biogas production of 13.2 $\mathrm{L} / \mathrm{d}$ was achieved at the mixing ratio of $60 / 40$.

\section{CONCLUSION}

The bench-scale hybrid upflow anaerobic sludge blanket
(HUASB) reactor was used to treat combined effluents of the real sugar industry and synthetic sago wastewaters. The maximum COD removal of $94.4 \%$ and the biogas production of $13.2 \mathrm{~L} / \mathrm{d}$ at $\mathrm{pH} 8.11$ was found at the mixing ratio of $60 / 40$ (sago/sugar industry wastewater). The $\mathrm{pH}$, VFA and alkalinity of the reactor effluent were under control for every $24 \mathrm{~h}$ of HRT which indicates the stability of the reactor. From the results obtained it was clear that HUASB reactor could be a very feasible alternative, eco-friendly and sustainable treatment system for the combined real sugar industry and sago wastewater.

\section{REFERENCES}

APHA 2005. Standard Methods for the Examination of Water and Waste- 


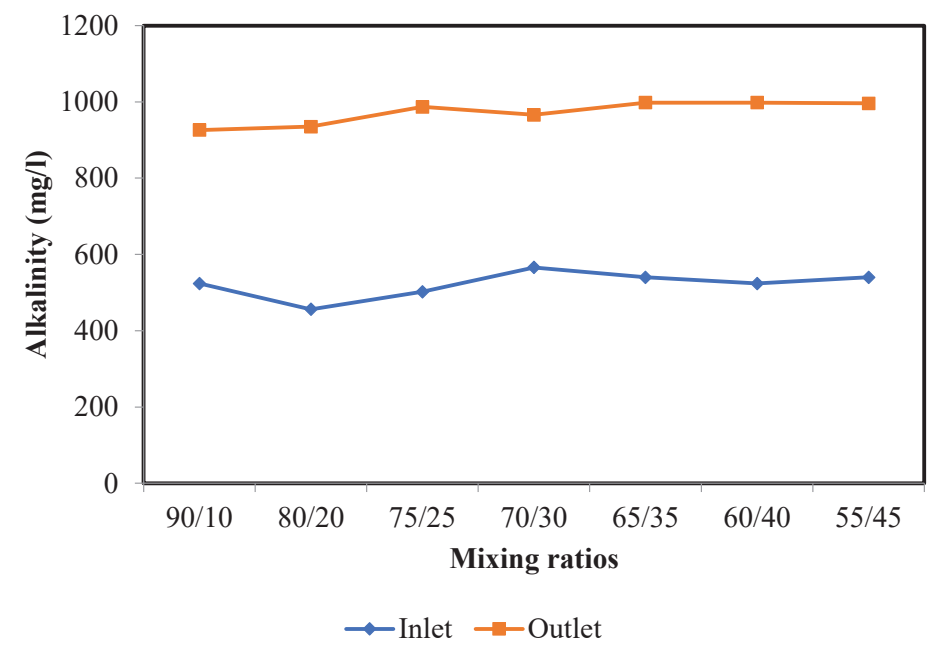

Fig. 6: Alkalinity at various mixing ratios.

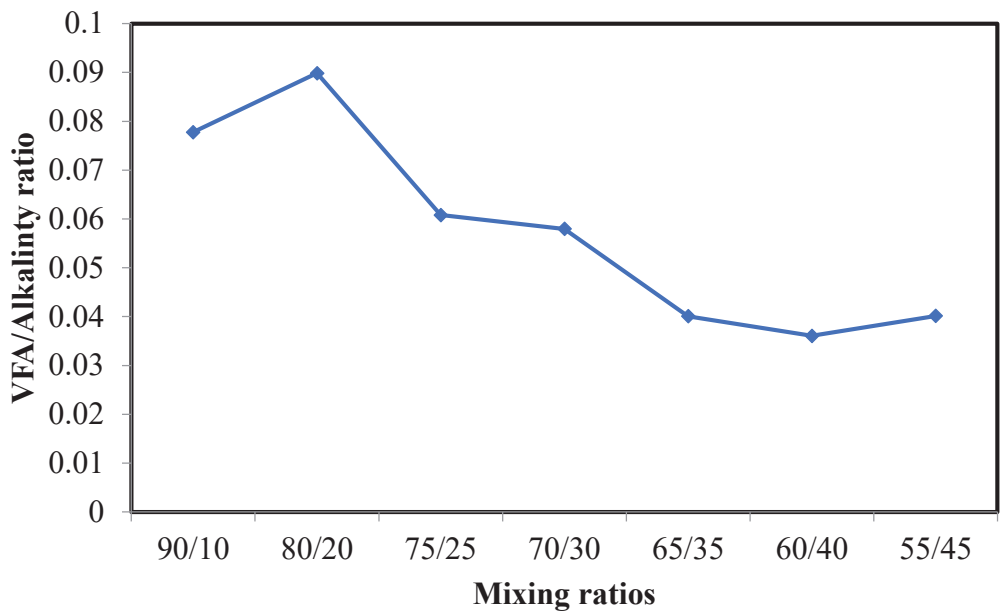

Fig. 7: VFA/Alkalinity at various mixing ratios.

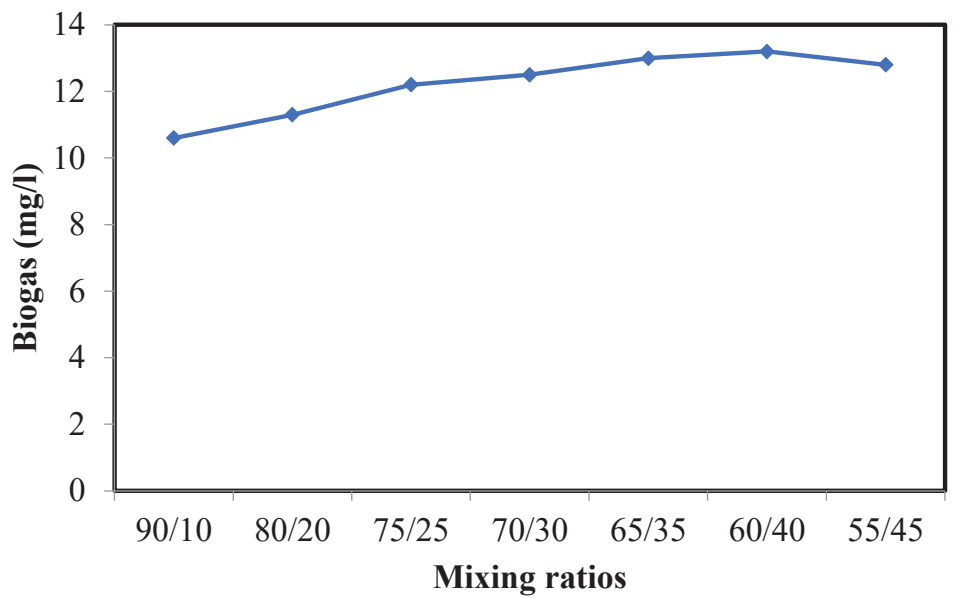

Fig. 8: Biogas production at various mixing ratios. 
water, $20^{\text {th }}$ edition. American Public Health Association, Washington DC, USA.

Arshad, A, Hashim, NH, Inthikhab, AQ and Athar, S 2009. Treatment feasibility of NSSC pulping effluent using UASB reactor, Journal of Water, Energy and Environment, 5: 57-60.

Ayati, B. and Ganjidoust, H. 2006. Comparing the efficiency of UAFF and UASB with hybrid reactor in treating wood fiber wastewater. Iranian Journal of Environmental Health Science and Engineering, 3(1): 39-44.

Behling, E., Diaz, A., Coline, G., Herrera, M., Gutierrez, E., Chacin, E., Fernandez, N. and Foster, C.F. 1997. Domestic wastewater treatment using a UASB reactor. Bioresource Technology, 61(3): 239-245.

Buzzini, A.P., Sakamoto, I.K., Varesch, M.B. and Pires, E.C. 2006. Evaluation of the microbial diversity in a UASB reactor treating from an unbleached pulp plant. Process Biochem., 41(1): 168-176.

Bhatti, ZI 1995. Problems encountered during the start-up of UASB reactor, Japanese Journal of Water Treatment and Biology, 31: 59-62.

Gnanapragasam, G., Senthilkumar, M., Arutchelvan, V., Sivarajan, P. and Nagarajan, S. 2010. Recycle in upflow anaerobic sludge blanket reactor on treatment of real textile dye effluent. World J. of Microbiology and Biotechnology, 26: 1093-1098.

Hampannavar, U.S. and Shivayogimath, C.B. 2010. Anaerobic treatment of sugar industry wastewater by upflow anaerobic sludge blanket reactor at ambient temperature. International Journal of Environmental Sciences, 1(4): 631-639.

Murthy, Y.S. and Patel, M.D. 1961. Treatment and disposal of sago wastes.
Report Submitted to the Central Public Health Engineering Research Institute, India.

Ndobeni. A., Oyekola. O. and Welz. P. J. 2019. Organic removal rates and biogas production of an upflow anaerobic sludge blanket reactor treating sugarcane molasses. South African Journal of Chemical Engineering, 28: 1-7.

Rein, P.,Turner, P. and Mathias, K. 2011. Good Management Practices for the Cane Sugar Industry. Int. Fin. Corp. Pub., pp. 1-696.

Sanchez, E., Borja, R., Traviesco, L., Martin, A. and Colmenarejo, M.F. 2005. Effect of organic loading rate on the stability operational parameters and performance of a secondary upflow anaerobic sludge bed reactor treating piggery waste. Bioresource Technology, 96: 335-344.

Saroja, K. and Sastry, C.A. 1972. Report on Treatment of Sago Wastes. National Environmental Engineering Research Institute, India.

Senthilkumar, M., Arutchelvan, V., Kanakasabai, V., Venkatesh, K.R. and Nagarajan, S. 2009. Biomineralisation of dye waste in a two-phase hybrid UASB reactor using starch effluent as a co-substrate. International Journal of Environmental and Waste Management, 3: 354-365.

Senthilkumar, M., Gnanapragasam, G., Arutchelvan, V. and Nagarajan, S. 2011. Treatment of textile dyeing wastewater using two phase pilot plant UASB reactor with sago wastewater as co-substrate. Chemical Engineering Journal, 166: 10-14.

Van Haandel, A.C. and Lettinga, G. 1994. Anaerobic Sewage Treatment: A Practical Guide for Regions with a Hot Climate. John Wiley and Sons, New York. 